\title{
KILLIAN- JAMIESON DIVERTICULA- A RARE CERVICAL OESOPHAGEAL DIVERTICULUM
}

\author{
A. Ganeshbala1, Ishani Borah², Arun Khosh ${ }^{3}$, Jinsha $A^{4}$
}

${ }^{1}$ Associate Professor, Department of ENT, Vinayaka Mission's Medical College and Hospital, Karaikal.

2Postgraduate Student, Department of ENT, Vinayaka Mission's Medical College and Hospital, Karaikal.

${ }^{3}$ Postgraduate Student, Department of ENT, Vinayaka Mission's Medical College and Hospital, Karaikal.

${ }^{4}$ Postgraduate Student, Department of ENT, Vinayaka Mission's Medical College and Hospital, Karaikal.

\section{ABSTRACT}

\section{BACKGROUND}

Killian-Jamieson (K-J) diverticulum is a true oesophageal diverticulum. It is a rare cervical oesophageal diverticulum and is infrequently encountered compared with Zenker's diverticulum. They are located just below the cricopharyngeal muscle, anteriorly and laterally, as a left sided or less commonly bilateral outpouching from the cervical oesophagus. In this report, we present a case of a 35-year-old male who presented with difficulty in swallowing, blocking sensation in the throat and sensation of lump in the neck since 3 years which is symptomatic Killian Jamieson diverticulum that distinguishes it from the more common Zenker's diverticulum. Killian-Jamieson diverticulum differs from Zenker's diverticulum in its location and mechanisms.

\section{KEYWORDS}

K-J Diverticulum, Zenker's Diverticulum, Diverticulopexy, Lump Neck.

HOW TO CITE THIS ARTICLE: Ganeshbala A, Borah I, Khosh A, et al. Killian- Jamieson diverticula- a rare cervical oesophageal diverticulum. J. Evolution Med. Dent. Sci. 2017;6(10):808-809, DOI: 10.14260/Jemds/2017/175

\section{BACKGROUND}

A Killian-Jamieson diverticulum is a rare cervical oesophageal diverticulum and was first described by Ekberg and Nylander in $1983.1^{1}$ It has also been referred to as a "proximal lateral cervical oesophageal diverticula" or as a "lateral diverticula from pharyngooesophageal junction area". Killian Jamieson (K-J) is a cervical oesophageal diverticulum, which is encountered rarely as compared to Zenker's diverticulum (ZD), with an incidence ratio of $1: 4 .^{2}$ Killian Jamieson diverticulum originates on the antero lateral wall of the cervical oesophagus through a muscular gap (Killian Jamieson space)below the cricopharyngeus and lateral to the longitudinal muscle of the oesophagus. This gap was first described by Killian and it represents the area where the recurrent laryngeal nerve enters the pharynx, whereas Zenker's Diverticulum develop at the anatomical weak posterior zone (Killian Dehiscence) just above the cricopharyngeal muscle.3,4,5 Killian Jamieson diverticulum are usually unilateral and only $25 \%$ are Bilateral. ${ }^{6}$

\section{CASE REPORT}

A 35-year-old male presented with difficulty in swallowing, blocking sensation of the throat and sensation of lump in the neck since a period of 3 years. Difficulty in swallowing was insidious in onset and progressive in nature and mostly for solids. He also experienced few symptoms like coughing during night and hoarseness of voice since 6 months. It was also associated with regurgitation of food particles following oral feeds along with epigastric pain.

Financial or Other, Competing Interest: None.

Submission 23-12-2016, Peer Review 19-01-2017,

Acceptance 25-01-2017, Published 02-02-2017.

Corresponding Author:

Dr. Ishani Borah,

Barla Manor, 20 Annai,

Indira Nagar

Sivan Koil Street,

Kheezakasakudy,

Karaikal, Pondicherry.

E-mail: scorpioivy18@gmail.com

DOI: $10.14260 /$ jemds $/ 2017 / 175$

\section{(c) $(1)(-$}

In 2001, Rubesin and Levine reviewed the records and pharyngo-oesophagogram of sixteen patients with K-J Diverticulum and found eleven with symptoms. ${ }^{1}$

An Examination of Head and Neck showed a single $6 \times 6 \mathrm{~cm}$ in size, diffuse swelling in the neck with normal skin over the swelling (Fig. 1). Swelling was firm in consistency and was mobile and did not move on deglutition. There were no associated systemic illnesses. His general physical examination and systemic examination including lymph node assessment was within normal limits. Examination of Ear Nose and Throat, were WNL.

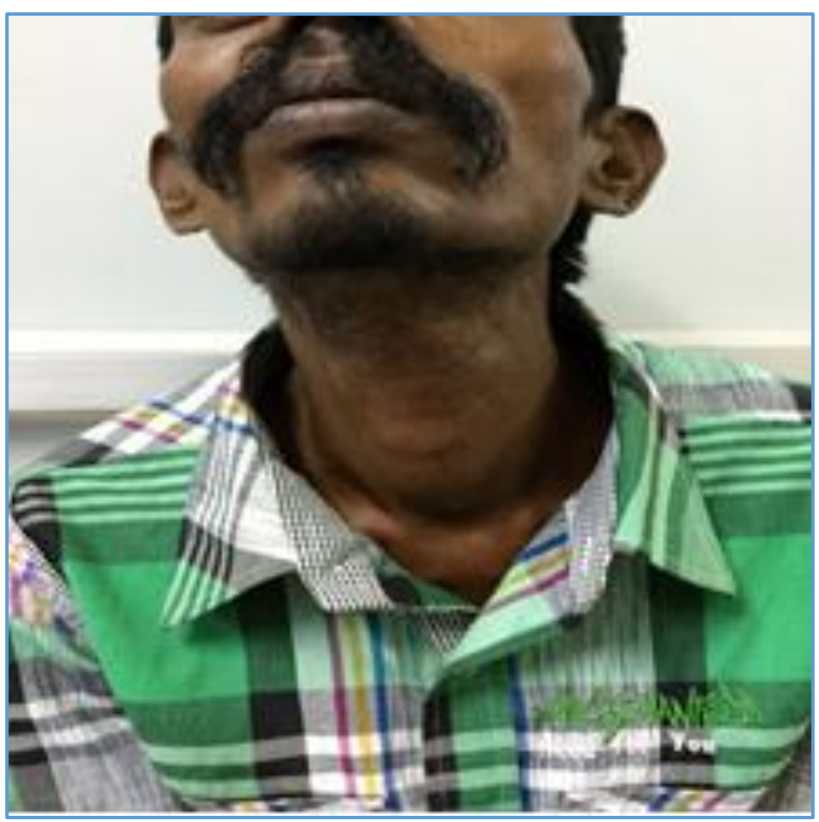

Figure 1

Contrast Oesophagogram was done (Fig: 2) and it revealed a well-defined sac like out pouching seen in the region of lower cervical oesophagus with complete nonvisualization of the thoracic oesophagus. Stomach was filled with air. 


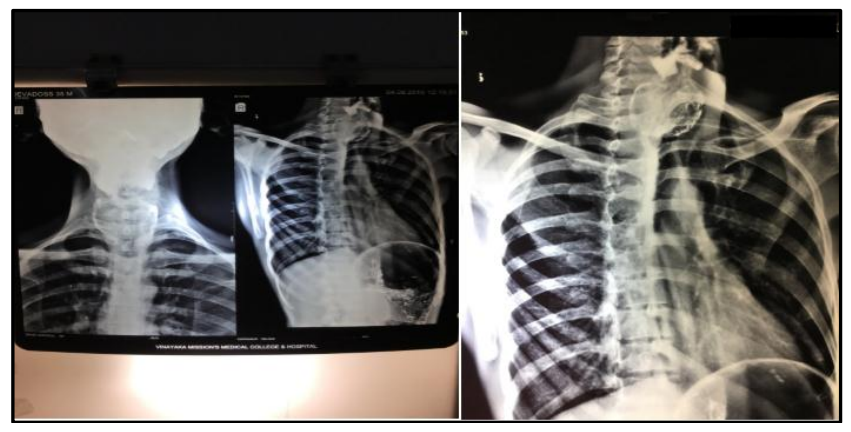

Figure 2

\section{Treatment}

Diverticulopexy done.

Patient came for follow up after 1 week. Patient symptomatically better.

\section{DISCUSSION}

A Killian Jamieson diverticulum is often unrecognized and misdiagnosed as a Zenker's diverticulum. It is not a true diverticulum as it does not involve all layers of the gastrointestinal wall.7 The pathogenesis of Killian Jamieson diverticula is unknown. However, it is likely that Killian Jamieson diverticula, in addition to Zenker's diverticula are acquired given the advanced age distribution of patient with this hypopharyngeal diverticula. Tang et al hypothesized that Killian Jamieson diverticula are the result of the functional outflow obstruction in the oesophagus in much the same way that a Zenker's diverticula is believed to result from a functional outflow obstruction in the pharynx.$^{3}$ The circular muscle fibers of the proximal oesophagus are believed in appropriately constrict during the act of swallowing. This may create high intraluminal pressure, which is then transmitted to the weakened area within the Killian Jamieson triangle.

On barium oesophagogram, Zenker's diverticulum is seen on lateral view often ${ }^{7}$ with contrast retained within the diverticulum. A prominent cricopharyngeal bar is often observed. A Killian-Jamieson diverticulum is seen on the lateral wall of the pharyngooesophageal junction on anteroposterior view and with contrast possibly being retained. 8,9

\section{REFERENCES}

[1] Ekberg 0, Nylander G. Lateral diverticula from the pharyngooesophageal junction area. Radiology 1983;146(1):117-22.

[2] Rubesin SE, Levine MS. Killian-jamieson diverticula: radiographic findings in 16 patients. Am J Roentgenol 2001;177(1):85-9.

[3] Tang SJ, Tang L, Chen E, et al. Flexible endoscopic killian-jamieson diverticulotomy and literature review (with video). Gastrointest Endosc 2008;68(4):790-3.

[4] Killian G. Über den mund der speiseröhre. Zeitschrift für Ohrenheilkunde 1908;55:1-44.

[5] Jamieson EB. In: Illustrations of regional anatomy. Edinburgh: Eand S, Livingstone Ltd 1934;(Section 2):44.

[6] Veenkar E, Cohen JI. Current trends in management of Zenker diverticulum. Curr Opin Otolaryngol Head Neck Surgery 2003;11(3):160-5.

[7] Chea CH, Siow SL, Khor TW, et al. Killian-jamieson diverticulum: the rarer cervical oesophageal diverticulum. Med J Malaysia 2011;66(1):73-4.

[8] Eckberg 0. Radiology of the pharynx and the esophagus. Springer 2004.

[9] Siow SL, Chea CH, Hashimah AR, et al. Adult intussusception: 5-year experience in Sarawak. Med J Malaysia 2011;66(3):199-201. 